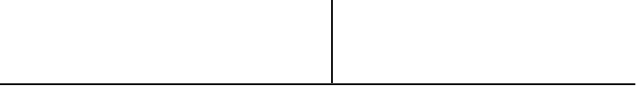

Rev. Latinoam. Psicopat. Fund., São Paulo, v. 11, n. 2, p. 286-297, junho 2008

\title{
Um sonho frio e seco: considerações sobre a melancolia*
}

Paulo José Carvalho da Silva

O termo melancolia tem uma longa história. Propomos, neste artigo, analisar os problemas da definição da melancolia no início da Idade moderna. Tratamos, em particular, da sua relação com a tristeza e, sobretudo, da produção de fantasias, delírios e sonhos nos melancólicos, conforme a medicina da alma dos séculos XVI e XVII.

Palavras-chave: Melancolia, tristeza, imaginação, história da psicopatologia

* Pesquisa realizada com apoio Fapesp, em especial auxílio para viagem de pesquisa junto à EHESS, em Paris. 
As várias histórias da melancolia, desde os estudos clássicos de Jean Starobinski (1960) e de Raimond Klibansky, Erwin Panofsky e Fritz Saxl (1964) até as mais recentes teses, testemunham que a melancolia é uma enfermidade que atormenta a humanidade há muitos séculos, tornando-se, inclusive, um assunto muito discutido, como, por exemplo, na Inglaterra do século XVII (Minois, 2003; Crignon-De Oliveira, 2006).

Constata-se também que os novos estudos sobre a melancolia, especialmente inseridos no campo da Psicopatologia Fundamental, levam sua longa história em consideração (Peres, 1996) ou, pelo menos, utilizam descrições históricas da paixão da tristeza como mais uma referência para compreender a melancolia, a partir de suas investigações clínicas de abordagem psicanalítica (Malucelli, 2007; Magtaz, 2008).

Nesta seção da Revista Latinoamericana de Psicopatologia Fundamental, já abordamos discursos da cultura luso-brasileira sobre a melancolia e a tristeza (Carvalho da Silva, 2006a e 2007b) e já discutimos casos dessa psicopatologia relatados por médicos, tais como Paolo Zacchia e outros (Carvalho da Silva, 2006 b e 2007a). Neste artigo, analisamos os problemas da definição da melancolia e investigamos, em particular, a sua relação com a tristeza e, sobretudo, a produção de fantasias, delírios e sonhos nos melancólicos, conforme a medicina da alma dos séculos XVI e XVII.

\section{Um difícil diagnóstico}

Na primeira modernidade, parece ter havido um uso fluido e abrangente do termo melancolia, inclusive, no meio médico. A palavra melancolia podia designar uma patologia, o humor bile negra (um dos quatro líquidos corporais, junto ao sangue, fleuma e bile amarela) ou uma compleição, isto é, um tipo psicofísico que o médico francês André Du Laurens (1597), por exemplo, afirma estar no limite da saúde (p. 113). Ele se refere 
ao temperamento melancólico conforme o antigo sistema hipocrático-galênico dos quatro temperamentos que identificam nas qualidades psicossomáticas as determinações do comportamento. Em resumo, os chamados fleumáticos, de qualidade fria e úmida, seriam naturalmente preguiçosos e insensíveis; os sanguíneos, de corpo quente e úmido, serenos e tranqüilos; os coléricos, quentes e secos, destemidos e irascíveis; já os melancólicos, frios e secos, apresentariam um comportamento marcado pela tristeza e temor.

O médico grego Hipócrates (c. 460-377 a.C.) afirma, nos Aforismos, VI-23, que quando o temor e a tristeza persistem um longo tempo, trata-se do estado melancólico. O que foi retomado por Cláudio Galeno (129-199) e pelos principais médicos de sua escola. Segundo essa corrente médica, os diferentes temperamentos produziriam as diferentes paixões, por exemplo, a ira decorreria do temperamento colérico e a tristeza adviria do temperamento melancólico. Mesmo não podendo identificar precisamente a causa, Galeno afirma que as alterações afetivas e cognitivas são expressões da situação dos humores:

Após numerosas pesquisas, eu não descobri porque quando a bile amarela se acumula no cérebro, somos acometidos de delírio, nem, no caso da bile negra, sofremos de melancolia, nem ainda porque a fleuma e as substâncias refrigerantes em geral provocam a letargia que desencadeia a perda da memória e da inteligência. (Galeno, 1995, p. 83; trad. nossa)

Por outro lado, Galeno também admite que as experiências afetivas seriam igualmente capazes de alterar a crase humoral, o que se verifica no De Locis Affectis (III, X), quando ele comenta que há alguns homens para os quais a essência da melancolia é o medo da morte.

Em geral, os médicos ingleses, franceses, italianos e espanhóis dos séculos XVI e XVII baseavam-se nessa tradição para pensar a melancolia, mas não sem dificuldades. Timothy Bright (1550?-1615), logo no primeiro capítulo de seu influente Treatise of Melancholie, adverte que o nome melancolia estava sendo usado de maneira muito diversificada. Segundo ele, a noção mais recorrente, porém, estabelece que há na melancolia uma disposição amedrontada de uma mente com a razão alterada ou um humor do corpo responsável por arruinar a razão. Para o médico inglês, a melancolia arrasta o enfermo para dentro das paixões da tristeza e do medo, com uma distração de sua capacidade racional.

O médico paduense Ercole Sassonia, no De melancholia tractatus (1620), descreve vários tipos de melancolia. Ele problematiza a noção comum de que a melancolia seria um delírio com temor e tristeza, e alega que conhecera melancólicos que não apresentavam delírio ou medo ou tristeza. Afirma a existência de melancólicos que têm imaginações e opiniões desordenadas sem nenhum temor ou tristeza: a essa classe pertencem os que sustentam serem reis, príncipes, car- 
dinais ou o anticristo. Sassonia relata ter conhecido em Veneza, onde clinicou durante muitos anos, um professor que se dizia o anticristo; um empregado que passava todo dia uma hora fechado em um cômodo com imagens pintadas de vários príncipes aos quais ele, do alto de uma tribuna, dava a bênção como se fosse o Sumo Pontífice, e ainda um nobre veneziano que afirmava ser constantemente procurado por todas as belas mulheres da nobreza. Esse último, por sinal, era contente e nada temeroso.

Sassonia (1620) menciona melancólicos, tristes e imaginativos que não apresentam temor, como aqueles que se crêem mortos ou feitos de barro:

O temor consiste em uma perturbação por um mal futuro, a tristeza consiste em uma perturbação que deriva da idéia de um mal presente; ora, aqueles que se encontram no pior de todos os males não têm nenhum temor porque não esperam nada de pior: por isso os melancólicos que crêem estarem já mortos ou serem feitos de barro não possuem ulteriores temores. (apud Dini, 1997, p. 60)

Enfim, o médico lembra os que são sempre temerosos e tristes sem nenhuma má imaginação. Sassonia afirma ter tratado muitas pessoas desse gênero, que não temiam algo específico ou que não se entristeciam por algum motivo claro, mas diziam que tudo causava suas aflições. Essa, sim, seria a verdadeira melancolia: “... esses mais do que todos eu chamo de melancólicos”, escreve o médico (apud Dini, 1997, p. 60).

O paduense identifica várias causas para a melancolia. De modo geral, elas seriam de três diferentes gêneros: o pensamento fixo, um desequilíbrio nas condições naturais do corpo ou uma causa externa, como um encantamento ou envenenamento.

André Du Laurens (1558-1609) também aponta múltiplas melancolias: aquela propriamente causada pelo humor seco e frio, outras advindas de misturas ou transformações de outros humores, um sintoma ou acidente da imaginação ou razão arruinada, aquela que tem sua sede no próprio cérebro etc.

Conforme a extensão da predominância da bile negra, ou humor melancólico, há três categorias diagnósticas sob a denominação genérica de melancolia: a melancolia essencial, a melancolia global e a melancolia hipocondríaca. A primeira se caracteriza pelo excesso ou corrupção da bile negra na cabeça. A segunda pela presença no corpo todo da bile negra, encéfalo incluso. E a terceira pelo mau funcionamento dos órgãos localizados na parte superior do abdômen, conhecida como hipocôndrio, em particular do estômago, com a conseqüente produção excessiva de bile negra e exalação de vapores escuros que perturbam as funções cerebrais. 


\section{Dupla infernal}

Tristeza e medo são afetos e não humores ou psicopatologias. No entanto, nas palavras do médico dos soberanos de França, esses dois afetos são "acidentes inseparáveis dessa miserável paixão" (Du Laurens, 1597, p. 118).

O famoso médico romano Paolo Zacchia (1584-1659) afirma que o excesso de humor melancólico torna a maioria dos indivíduos, além de tristes e temerosos, amantes da solidão, chorosos, taciturnos, tímidos e facilmente desgostosos mesmo daquilo que antes consideravam prazeroso.

Determinados hábitos e experiências afetivas eram identificados pelos médicos como desencadeadores e/ou sintomas da melancolia. Uma má educação ou uma vida sedentária e excessivamente meditativa poderiam provocar os males melancólicos, bem como o luto e a infelicidade no amor. Cabe ressaltar, entretanto, que se pensava, como explica o médico oficial do Reino de Nápoles e da corte pontifícia, Luca Tozzi (1638-1717), que a diferença fundamental entre um melancólico e alguém apenas triste se dá pelo fato de não haver uma causa manifesta da tristeza sofrida pelo melancólico.

A dimensão temporal também era uma referência crucial para a definição do diagnóstico. Benedetto Silvatici (1575-1668) exemplifica que, na melancolia, não basta haver temor e tristeza, esses afetos devem ser crônicos. O professor de medicina prática e teórica da Universidade de Pádua relata o caso de uma mulher que teria sido privada do afeto dos pais há 37 anos e, desde então, nada teria sido capaz de mudar sua condição melancólica, nem mesmo o casamento e a maternidade. As imagens da infância teriam sido impressas em profundidade e perturbariam sua alma constantemente ao fazer com que seu corpo procurasse afastar um objeto estranho e prejudicial, presente apenas em sua imaginação. Essa desordem no campo da imaginação com efeitos motores explicaria também porque muitos melancólicos sofreriam de sonambulismo e tantos outros teriam dificuldades de ficarem parados.

Na longa e minuciosa dissecação da melancolia realizada por Robert Burton (1577-1640), destaca-se a violência de uma dor atemporal, infinita, que se prolonga e se atualiza levando à eliminação da possibilidade de sentir prazer na relação com o mundo exterior e ao ódio a si mesmo. Os melancólicos não podem ter prazer, não podem evitar a tristeza: “... mesmo se correm ou se descansam, acompanhados ou sozinhos, esse sofrimento continua: irresolução, inconstância, vaidade, medo, tortura, preocupação, ciúmes, suspeitas, etc. persistem e não podem ser aliviados" (Burton, 1638, p. 184).

Burton (p. 105) considera que descontentamentos, preocupações e infortúnios estão entre as principais causas e sintomas da melancolia e são, na maioria das vezes, acompanhados por angústia e dor. No entanto, a tristeza é sua com- 
panheira inseparável, tal como seriam inseparáveis os santos Cosme e Damião. É o mais comum sintoma e também pode ser a causa. Mesmo quando caem em gargalhadas, os melancólicos não podem escapar da tristeza:

Logo que abrem os olhos, após terríveis e inquietantes sonhos, os seus pesados corações começam a lutar: continuam aflitos, perseguindo, duelando, sofrendo, reclamando, encontrando faltas, resmungando, mostrando rancor, chorando, (...) recriminando a si mesmos, inquietos, com pensamentos desassossegados, descontentes consigo, com outras pessoas e com as coisas públicas que lhes concernem ou não, do passado, do presente ou do futuro. (p. 183-4)

\section{Sonho frio e seco}

A descrição de Burton faz pensar na melancolia como um estado onírico sombrio e perturbador, ou melhor, como uma espécie de continuidade entre o pesadelo e a vida. Com efeito, são vários os médicos do período que examinam as relações entre melancolia e a chamada laesa imaginatio, ou seja, uma perturbação na capacidade de produzir imagens sobre si mesmo e o mundo circundante. Essa perturbação se caracteriza pela falta de controle da faculdade racional sobre a formação involuntária de imagens mentais. Na melancolia, como no sonho, a imaginação torna-se mais forte do que a razão. Crignon-De Oliveira (2006, p. 266-271) explica que, segundo os ingleses seiscentistas, tanto a melancolia quanto o entusiasmo podem implicar uma fragilidade da alma que se torna incapaz de colocar à prova suas próprias representações.

O texto pseudo-aristotélico Problema $X X X$ associa a capacidade criativa dos poetas à melancolia, idéia que sofreu várias interpretações no Renascimento (Schleiner, 1991). Além dessa máxima antiga, houve quem afirmasse o contrário, isto é, que o trabalho mental poderia provocar a melancolia. Para o humanista florentino Marsílio Ficino (1489) o exercício da filosofia acarreta uma separação entre alma e corpo, o que, por sua vez, engendra o mal melancólico.

Uma mente que se desprende da percepção ordinária do mundo podia sinalizar melancolia. Zacchia (1655) descreve melancólico convicto de estar morto, ter um animal vivo dentro de si, possuir parte do corpo composta de vidro, ou ter sido transformado em um animal como um lobo, urso ou pássaro (Carvalho da Silva, 2006b).

Vale observar que, influenciados pelas Metamorfoses de Ovídio ou não, muitos médicos, de diferentes nacionalidades e épocas, associaram casos de delírios de metamorfose à melancolia. O médico e filósofo islâmico Avicena (980-1037) já descrevia, entre outros tormentos da bile negra, pessoas que se diziam transformadas em leões, diabos, pássaros ou ursos (Pigeaud, 2006, p. 82). 
Pesadelos com cenas aterrorizantes também fazem parte do quadro clínico da melancolia hipocondríaca, o que inclui perseguições, sufocação, afogamento, devoração por animais ferozes, sepultamento etc. Contudo, o próprio Zacchia adverte que ninguém se torna louco apenas por imaginar coisas. Somente é louco aquele que imagina coisas que não existem, e a sua razão não tem condições de discernir a fantasia da realidade, tomando como verdadeiro o que é falso e confirmando a ilusão (1655, p. 292).

Michael MacDonald (1981) explica que na Inglaterra do século XVII ilusões extravagantes e alucinações também eram atribuídas à melancolia. A conexão lógica entre as ilusões e as emoções patológicas, identificadas como melancólicas, reside no descompasso entre os afetos experimentados e as supostas causas dos mesmos. A tristeza não seria, portanto, uma condição sine qua non para o diagnóstico de melancolia, mas o afeto mais comum dessa psicopatologia cujo fundamento seria a ilusão, sobretudo aquela que faz com que alguém sinta medo ou dor quando não experimentaram um perigo ou perda significativa.

Conforme o médico espanhol Lobrera de Avila (1542) deve-se tratar os melancólicos com muita cautela. É necessário usar de argumentos racionais para combater seus pensamentos, corrompidos pelos vapores que chegam ao cérebro por meio da movimentação do humor melancólico. Nesse processo, entretanto, não se deve contradizer o paciente. Ele dá o exemplo de um melancólico que dizia não conseguir adormecer porque tinha dentro de sua cabeça um punhal muito afiado. O procedimento correto é o médico dizer que acredita em seu paciente, e que ele pode se livrar do perigo ao se submeter ao tratamento. Esse é baseado na extração do excesso de humor melancólico com ajuda de purgantes e adequação da dieta, mas tudo isso deve ser realizado sem contradizer a imaginação do enfermo. Nesse caso, pediu-se a um barbeiro que simulasse uma cirurgia, realizando uma incisão inofensiva, a fim de extrair o punhal imaginário de sua cabeça.

Du Laurens explica que as enfermidades recebem o nome conforme o local que atacam, os acidentes que provocam ou as suas causas. No caso da melancolia, o nome vem do humor melancólico, mas a sua definição consiste numa "rêverie" sem febre, pois, para ele, todos os melancólicos têm a imaginação perturbada e alguns têm até a razão abalada.

As imaginações dos melancólicos seguem a disposição do corpo, isto é, as qualidades da bile negra, embora de modo individual, tal como diferentes pessoas ficam embriagadas de modo diferente com o mesmo vinho. De modo geral, ao se depositar no cérebro, o humor causaria imaginações de caráter frio e terroso. As imaginações podem também ser causadas diretamente na alma por meio do estilo de vida ou dos estudos empreendidos pelos melancólicos. As paixões pessoais imprimem sua tonalidade na imaginação melancólica. Por exemplo, os ambiciosos, ao se tornarem melancólicos, imaginam-se reis e imperadores; os 
amorosos correm atrás da sombra de seu amor. Há também a possibilidade de alguma influência sobrenatural nas imaginações muito estranhas.

O médico francês precisa que há uma correspondência entre a produção dos sonhos e das imaginações melancólicas e que ambos podem ter os três tipos de causas: “... sonho se reporta à imaginação tão quanto a melancolia. Nós temos três tipos de sonhos: uns são naturais, outros da alma, e os últimos de algo acima dos dois primeiros" (Du Laurens, 1597, p. 134 v.).

Nem toda dor da alma é melancolia. Timothy Bright (1586) distingue a melancolia do mal de consciência. A diferença fundamental seria a causa. Aquele que se encontra atormentado pela culpa, ao fazer o exame de consciência, pode identificar as causas de seus sintomas no pecado cometido. Já o melancólico não identifica facilmente a causa de seus tormentos. Em suas palavras: "A melancolia dispõe ao medo, à dúvida, à desconfiança e ao pesar, mas tudo sem uma causa" (p. 192).

Há também um aspecto social implicado na escolha dos termos para definir as psicopatologias. De acordo com MacDonald (1981) houve na Inglaterra seiscentista uma verdadeira moda melancólica, especialmente entre os aristocratas. Ele afirma (p. 151) que os nobres apreciavam serem retratados como melancólicos. Por outro lado, os termos distúrbio mental (troubled in mind) e deprimido (mopish) eram menos utilizados pelos próprios aristocratas ao descrever seus estados psíquicos.

Luca Tozzi (1687) aponta outras referências importantes na identificação da melancolia. O médico afirma que o melancólico não apresenta déficit de memória ou febre. Ele eventualmente não verbaliza as coisas absurdas que medita e as exprime por meio de gestos e ações. Em outros casos, a língua torna-se desenfreada e titubeante, emite sons estranhos e o melancólico exprime confusamente suas idéias.

Em suma, os médicos da primeira modernidade apresentam nuanças na compreensão da melancolia e discordam até mesmo sobre a necessidade da presença da tristeza, e sobre a extensão da laesa imaginatio. No entanto, em geral, conforme a medicina da alma do período, a melancolia forma uma parceria infernal com a tristeza e seus acidentes incluem a lenta destruição do corpo e a ruína dos relacionamentos. O medo, o desgosto, a solidão, a inquietude eram também sinais dessa psicopatologia.

O sonho era um modelo para se entender a própria melancolia: um sonho sombrio e interminável, que arrasta o sonhador para o tudo ou o nada. E, sobretudo, um sonho frio e seco: que esfria e seca o desejo.

É interessante notar, por um lado, a atualidade das discussões desses médicos sobre a melancolia e, por outro, como o assunto está longe de ser encerrado. Freud, em "Luto e melancolia" (1916) descreve um estado de ânimo 
profundamente doloroso e um desinteresse pelo novo. A diferença fundamental da melancolia seria a perda a mais, a perda de um objeto inconsciente, havendo, portanto, a dor de uma perda de parte de si. Por essa razão, no luto, o mundo parece empobrecido; na melancolia, é o Eu que se empobrece. Os reproches a um objeto erótico perdido retornam ao Eu devido a uma identificação com o mesmo. Com a perda do que se amava, surge o ódio a si mesmo que, de certa forma, os médicos têm observado nos melancólicos há séculos.

No âmbito dos mais recentes estudos em Psicopatologia Fundamental, Malucelli (2007), por meio de sua análise de um caso atual de Síndrome de Cotard, mostra a permanência dos delírios de negação do corpo e afirmação da morte, da mania de grandeza e pequenez, do mutismo, do horror, da angústia permanente, da paralisia, do pesadelo, da dor de existir e, sobretudo, da aniquilação do desejo e da violência da tristeza que acompanha a melancolia sem se confundir com ela. Marraccini (2007) fala de um eu em ruína, aprisionado entre o tudo e o nada, na experiência da perda. Magtaz (2008) discute a amplitude do diagnóstico de melancolia, ao retomar a categoria freudiana de melancolia enquanto neurose narcísica, e discorre, não sobre imaginação - como os médicos dos séculos XVI e XVII - nem alucinação ou delírio, mas sobre ilusão negativa. Escreve também sobre defesas perante uma tristeza que não pode ser reconhecida como tal e que se manifesta nas fantasias de devoração e de deformação corporal, também presentes na literatura médica aqui analisada.

Como outros médicos de sua época, Du Laurens elenca várias histórias de imaginações melancólicas, dedicando um capítulo inteiro de seu livro ao tema. Algumas dessas histórias eram muito conhecidas no meio médico europeu, como relata MacDonald (1981) a propósito de um homem que acreditava ter o nariz do tamanho de uma casa, e de outro que temia inundar uma cidade inteira se urinasse.

Aliás, Du Laurens introduz esse capítulo afirmando que apresenta esses casos estranhos para o deleite do leitor, o que confere um colorido tragicômico a uma triste psicopatologia. Talvez esse tenha sido o modo que ele encontrou para amenizar o peso do objeto de investigação ou mesmo a maneira de abordar, mesmo que de modo tangencial, o que há de mais desafiante no tratamento da melancolia: possibilitar ao melancólico rir de si mesmo.

\section{Referências}

BRIGHT, T. Treatise of Melancholie. London: John Windet, 1586.

Burton, R. The anatomy of melancholy: what it is, with all the kinds, causes, symptomes, prognostickes and several cures of it (...).Oxford: Cripps, 1638. 
Carvalho da Silva, P. J. Sobre um mal universal. Revista Latinoamericana de Psicopatologia Fundamental, São Paulo, v. IX, n. 3, p. 533-537, set. 2006.

. O romano que virou pássaro: considerações sobre o relato de caso. Revista Latinoamericana de Psicopatologia Fundamental, São Paulo, v. IX, n. 4, p. 701-705, dez. 2006.

. A dor enquanto paixão. Revista Latinoamericana de Psicopatologia Fundamental, São Paulo, v. X, n. 1, p. 51-62, mar. 2007.

. Do príncipe triste ao rei médico de almas. Revista Latinoamericana de Psicopatologia Fundamental, São Paulo, v. 10, n. 4, p. 696-710, dez. 2007.

Crignon-de Oliveira, C. De la mélancolie à l'enthousiasme. Robert Burton (1577-1640) et Anthony Ashley Cooper, comte de Shaftesbury (1671-1713). Paris: Honoré Champion, 2006.

Du LaUrens, A. Discours de la conservation de la vue, des maladies melancholiques, des catarrhes, \& de la vieillesse. Paris: Jamet Mettayer, 1597.

Ficino, M. (1489). Sulla Vita. Milano: Rusconi, 1995.

Freud, S. (1916). Trauer und Melancholie. In: Gesammelte Werke. Frankfurt am Main: Fischer Verlag, 1981. v. X, p. 427-446.

Galeno, C. L'âme et ses passions. Les passions et les erreurs de l'âme. Les âmes suivent les tempéraments du corps. Tradução e notas de V. Barras, T. Birchler, A-F. Morand. Paris: Les Belles Lettres, 1995.

. Oeuvres médicales choisies II. Des facultés naturelles. Des lieux affectés. De la méthode thérapeutique, à glaucon. Trad. francesa C. Daremberg. Paris: Gallimard, 1994. Hipócrates. De l'art médical. Trad. francesa por E. Littré. Paris: Bibliothèque Classique, 1994.

Klibansky, R.; Panofsky, E.; Saxl, F. Saturn and Melancholy. Studies in the History of Natural Philosophy, Religion, and Art. New York: Basic Books, 1964.

Lobrera de Avila, L. Vergel de Sanidad (...). Alacala: Joan de Brocar, 1542.

MacDonald, M. Mystical Bedlam. Madness, anxiety and healing in Seventeenthcentury England. Cambridge: Cambridge University Press, 1981.

Magtaz, A. C. Distúrbios da oralidade na melancolia. 2008. Tese (Doutorado em Psicologia Clínica), Pontifícia Universidade Católica de São Paulo - PUC-SP, 2008.

Malucelli, D. S. Síndrome de Cotard: uma investigação psicanalítica. 2007. Tese (Doutorado em Psicologia Clínica), Pontifícia Universidade Católica de São Paulo - PUC-SP, 2007.

Marracini, E. M. O eu em ruína: um estudo psicanalítico sobre a perda. 2007. Tese (Doutorado em Psicologia Clínica), Pontifícia Universidade Católica de São Paulo - PUCSP, 2007. 
Minors, G. Histoire du mal de vivre. De la mélancolie à la dépression. Paris: Éditions de La Martinière, 2003.

Peres, U. T. (Org.). Melancolia. São Paulo: Escuta, 1996.

Pigeaud, J. Délires de métamorphose. Gesnerus. Swiss Journal of the History of Medicine and Sciences, Zurique, v. 63, p. 73-89, 2006.

SAssonia, E. De melancholia tractatus. Venezia: Alexandrum Polum, 1620, p. 7-10, apud DinI, A. (Org.). Il medico e la follia. Cinquanta casi di malattia mentale nella letteratura medica italiana del Seicento. Firenze: Le Lettere, 1997. p. 55-62.

SCHLeIner, W. Melancholy, genius, and utopia in the Renaissance. Wiesbaden: Otto Harrassowitz, 1991.

Silvatici, B. Consiliorum et responsorum medicinalium centuriae quatuor. Genevae: Antonii et Samuelis De Tournes, 1662, p. 58-62, apud Dini, A. (Org.). Il medico e la follia. Cinquanta casi di malattia mentale nella letteratura medica italiana del Seicento. Firenze: Le Lettere, 1997. p. 82-89.

StARoBinski, J. Histoire du traitement de la mélancolie des origines à 1900. Bâle: Acta psychosomatica, 1960.

Tozzi, L. Medicinae pars altera. Venezia: Nicolaum Pezzana, 1687/1711, p. 149-150, apud DiNI, A. (Org.). Il medico e la follia. Cinquanta casi di malattia mentale nella letteratura medica italiana del Seicento. Firenze: Le Lettere, 1997. p. 97-98.

Zacchia, P. De'mali hipochondriaci. Libri tre. Veneza: Paolo Baglioni, 1655.

\section{Resumos}

(Un sueño frío y seco: consideraciones sobre melancolía)

El término melancolía tiene una larga historia. En este artículo nos proponemos analizar los problemas de la definición de la melancolía en el inicio de la edad moderna. Tratamos en particular de su relación con la tristeza, sobretodo de la producción de fantasías, delirios y sueños en los melancólicos, conforme la medicina del alma de los siglos XVI y XVII.

Palabras clave: Melancolía, tristeza, imaginación, historia de la psicopatología

(Un rêve froid et sec: considérations sur la mélancolie)

Le mot mélancolie jouit d'une longue histoire. Le but de ce travail est d'investiguer les enjeux de la définition de la mélancolie au début de l'époque moderne. On analyse, en particulier, ses rapports avec la tristesse et avec la production 
de fantaisies, de délires et de rêves selon la médicine de l'âme des XVI et XVII siècles.

Mots clés: Mélancolie, tristesse, imagination, histoire de la psychopathologie

(A cold, dry dream: considerations on melancholia)

The term melancholia is an old one. This article analyses the problems in defining melancholia at the beginning of the modern age. We deal in particular with the relations of this condition with sadness and, especially, with the production of fantasies, deliria and dreams according to the language of the medicine of the soul of the 16th and 17 th centuries.

Key words: Melancholia, sadness, imagination, history of psychopathology

Versão inicial recebida em abril de 2008

Versão aprovada para publicação em abril de 2008

\section{Paulo José Carvalho da Silva}

Psicólogo; psicanalista; mestre em História da Ciência pela Pontifícia Universidade Católica de São Paulo - PUC-SP; doutor em Psicologia pela Universidade de São Paulo - USP (São Paulo, SP, Brasil); professor doutor do Programa de Estudos Pós-Graduados em História da Ciência, Pontifícia Universidade Católica de São Paulo - PUC-SP (São Paulo, SP, Brasil), membro da Associação Universitária de Pesquisa em Psicopatologia Fundamental (São Paulo, SP, Brasil).

Rua Cajaíba, 15

05025-000 São Paulo, SP, Brasil

Fone: (11) 9248-9202

e-mail: paulojcs@hotmail.com 